\title{
EXTENDED ROLES AND
}

\section{RESPONSIBILITIES OF}

\section{LIBRARY ASOSCIATION WEB SITES}

\section{RUWAN GAMAGE ${ }^{1}$}

BSc (Colombo), MLS (Colombo), PhD (Wuhan, PRC).

\section{Abstract}

Library associations have used Web based mediums from a long time to disseminate information to their membership. However, most of these sites were static, and were not updated frequently. This is mainly due to the lack of time \& user friendly technologies.

Present Web 2.0 technologies have enabled easy designing and maintenance of Web sites. This paper mainly introudce such technologies and enabled features employed in redesigning the University Librarians Association (ULA) of Sri Lanka web site. It also discuss some changes concurrently taken place in a few other library association web sites.

It is evident that Web site renovation should be a well planned process, and that due to addition of new services and features, associations can climb up to higher levels of user interaction.

Keywords: Web site redesigning, Content management systems, Library associations, University Librarians Association, Sri Lanka Library Association

\footnotetext{
${ }^{1}$ Senior Assistant Librarian, Library, University of Moratuwa (mailruga@gmail.com)
} 


\section{Introduction}

Everything on earth be subject to evolution; so are Web sites. The present Web technology is transforming the WWW through a few paradigm shifts called Web 2.0 and Web 3.0. On par with these changes, libraries also evolve through a similar process. Corresponding terms are Library 2.0 and Library 3.0.

Library Association Web sites respond to these changes facilitating their clientele exchange ideas with peers, and allowing them to know and react in no time. New roles are being assigned to professional editors, marketers and Web designers, sometimes blurring boundaries of all these professions. The author is going to review changes appeared in University Librarians Association (ULA) Web site over the past year, and relate that to trends evident in other library association Web sites.

\section{Changes in ULA Web site}

At the start of the term of the author as the editor in July 2008, ULA Web site had been updated on a few instances only, such that for announcing the annual conference, and special events. The look and feel was static. It was not inviting members to regularly visit and get informed. At the time, it was the blueprint in many Web sites, if not all, over the country. This was a time when library 2.0 was hanging about. The free and open source (FOS) content management system (CMS) called Joomla had released its revolutionary 1.5 version on the same year. The author had a chance to undergo a training on Joomla, sponsored by the staff development center of University of Moratuwa. This was one turning point of the ULA Web site. A redesigning drive got started immediately.

Supported by the association president's eagerness to develop the Web site as a dynamic information and marketing medium, and also by his and fellow members' feedback and encouragement, a complete professional site was ready in no time. Another reason for success was the complete freedom given to the editor by the ULA Exco for designing and maintaining the Web site. 


\subsection{Interactivity}

One of the salient features of Web 2.0 (or library 2.0) is strong interactivity. In the ULA Web site, we have enabled anyone to give feedback on any issue, on the common feedback form. In addition, we recently introduced the 'in-context feedback' feature to enable commenting on individual articles.

\subsection{Community building}

Joomla extensions ${ }^{1}$ support building up advanced communities. However, this was not fully utilized. Instead, the inbuilt signup facility was made available. Anyone could register themselves and join the community. However, only the members were upgraded to the state of 'special users'. Initially, memberspecific notices were made visible only after signing-in to the site. Nevertheless, the interest of members to sign in was low. Therefore, at a later stage, everything was made publicly accessible. Yet, the sign in feature was not removed. It continues to facilitate easy communication among members.

\subsection{Content richness}

ULA started a marketing campaign named 'Information for Improvement' during the year. The main idea was to give ready access to ULA-born information resources. Therefore existing resources (journals, newsletters, and conference articles) were converted to e-format. These e-resources were hosted mainly under the ULA e-Library menu item.

\subsection{Blogging}

The main idea of the Editor's Blog was to record changes applied to the Web site. However, it has been developed into a journal of thoughts related to library science. It is only the second blog in Sri Lanka, by a Sri Lankan librarian.

1 Third party software developed by companies or individuals to enable different functionalities within the Joomla framework. These can be free or commercial, irrespective of the usefulness of the extension. 


\subsection{Currency and effectiveness}

One of the main targets of the redesigning project was to make it dynamic and current. Therefore news on current happenings in ULA and in the local LIS scene was promptly updated. As a result, ULA Web site became the sole newswire for updating the whole LIS community about new developments.

In addition, ULA created predictable content to be auto displayed using inbuilt features of Joomla. For example, an article on the World Book Day was created sometime before the event, and instructed the article to appear automatically on the particular day (23 April), and further to be archived after a given period. This prevented management flaws inhibit displaying and removing time sensitive articles on time.

\subsection{Easy integration}

RSS and Atom feeds have revolutionized the concept of 'reading'. Now, anyone can have his own RSS reader, and read all posts in most Web sites from one interface. There is no need to visit other Web sites, examining if they have been updated since your last visit. ULA is no exception. Joomla enables simple syndication of site content, as well as aggregating news from other sites. This was employed in designing the 'Conference Alerts' (CA) facility. CA is not updated by ULA, but aggregates LIS conferences appearing in an external site.

\subsection{Promotion}

The Web site was promoted through word of mouth communication, and also by using Sri Lanka Library Friends eGroup. ULA Journal (JULA) was also hosted in Sri Lanka Journals Online (SLJOL). There, a link has given back to the Web site.

ULA site was optimized for popular search engines, including Google. Currently it comes inside the first 3 results for many related searches. 
In addition, as a method of attracting users, the Web site hosted several types of e-greetings on special occasions such as New Year and Vesak festival. This feature was very much popular and has the potential of attracting international users too.

\subsection{Usage}

ULA maintained usage statistics of the ULA web site.

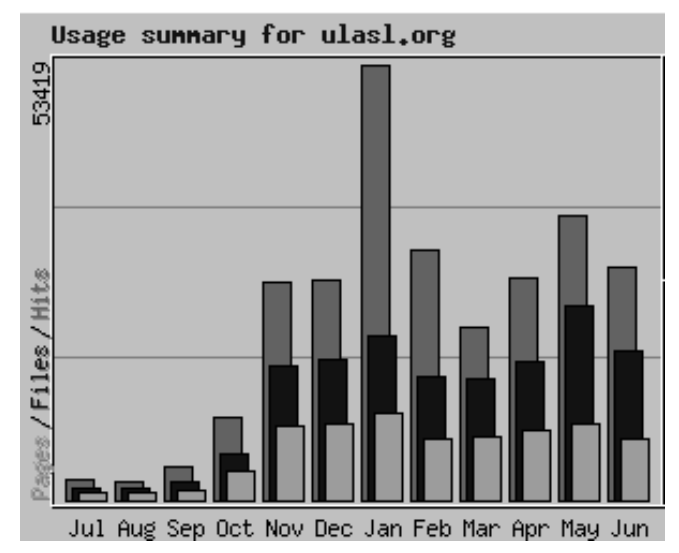

Fig. 1. Usage statistics for ulasl.org

It was found that from October-Novamber 2008 to date, there had been a steady growth in usage, with the exception of January, 2009, which reorded the highest usage. This was due to the renovation activites and addition of new resources to the web site. In addtion, marketing approaches initiated from time to time affected usage a great deal.

\section{Other library association Web site renovation projects}

\subsection{International Federation of Library Associations (IFLA) ${ }^{1}$}

IFLA's web site was a mere collection of links as shown in Fig 2. The new web site (Fig.3 \& 4) was lanched in April 2009.

\footnotetext{
${ }^{1}$ http://www.ifla.org
} 


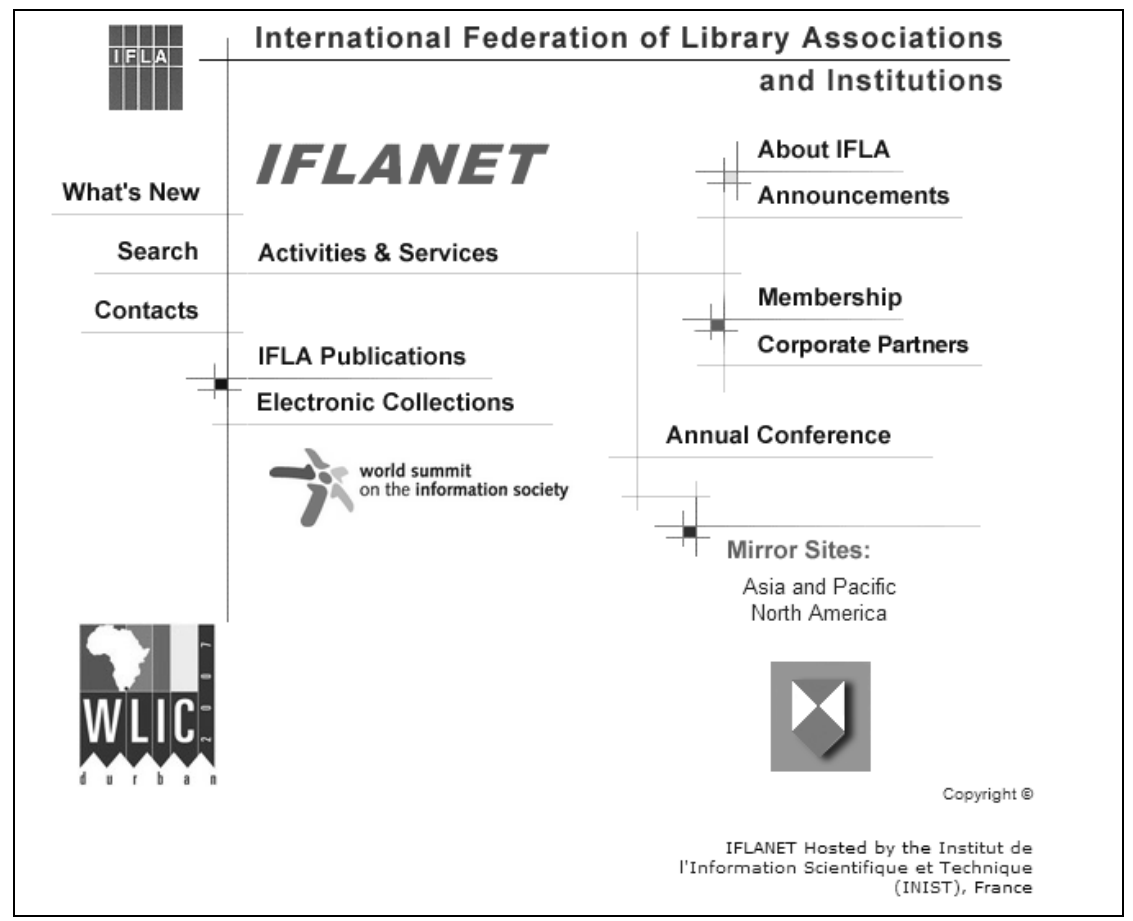

Fig.2. A screen shot of the IFLA Web site archived in 07.07.2008.

At the Web site lanching ceramony, Claudia Lux, IFLA President was quoted saying...

"I congratulate the IFLA staff with this achievement and after just a glance and bit of surfing, it is quite clear that the new website is realizing the potential of the Web 2.0 world. It will become a powerful and dynamic communication platform for the whole IFLA community."

- Claudia Lux, IFLA President

An overview of the site attracts our attention to the following features (New IFLA Web Site - see references). 
Journal of the University Librarians Association of Sri Lanka. Vol.13 (Issue 1). 2009

1. Modern, standards-compliant design

2. Highlights IFLA's activities andsuccesses

3. Tools for units and committees to work online

4. Ability to add more multilingual content

5. RSS and email notification

As ULA site was developed using Joomla, IFLA has used another open source CMS called Drupal ${ }^{1}$.

Designing of a new site was not loosely taken. It was developed with the guidance of a working group assigned by IFLA (Craven, 2008).

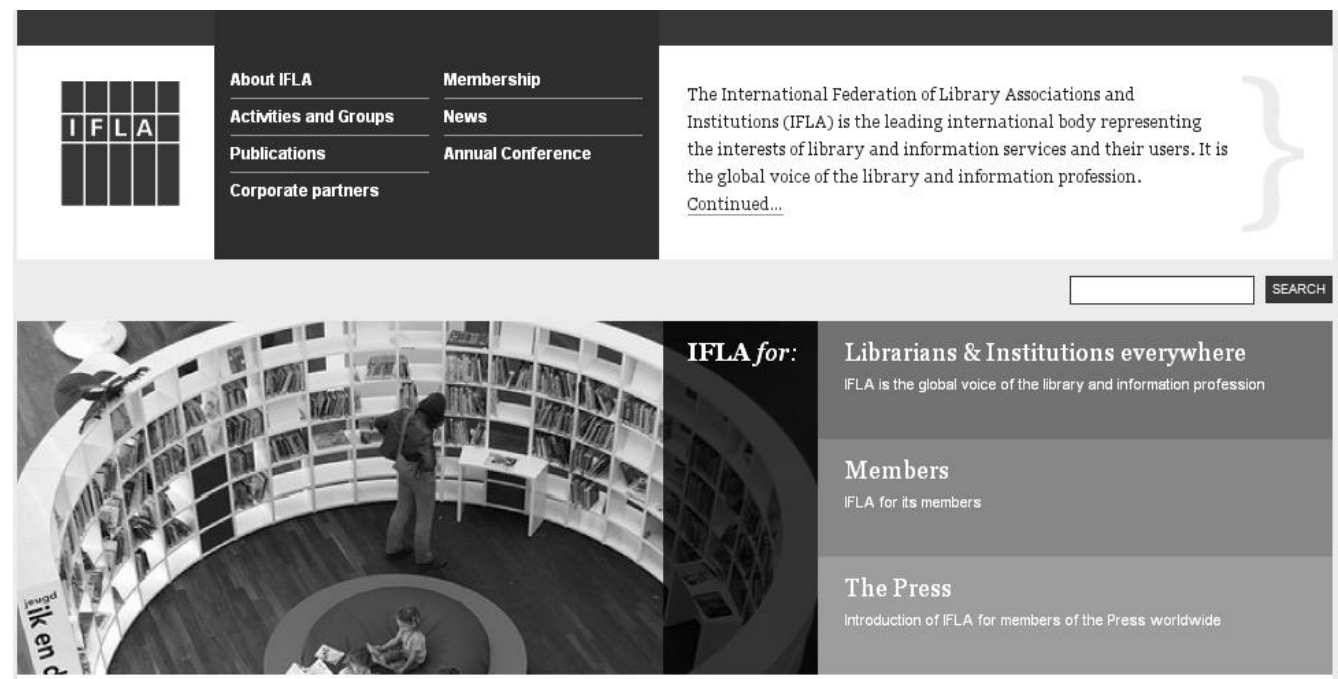

Fig.3. Screen shot of the renovated IFLA Web site.

\footnotetext{
${ }^{1}$ http://www.drupal.org
} 


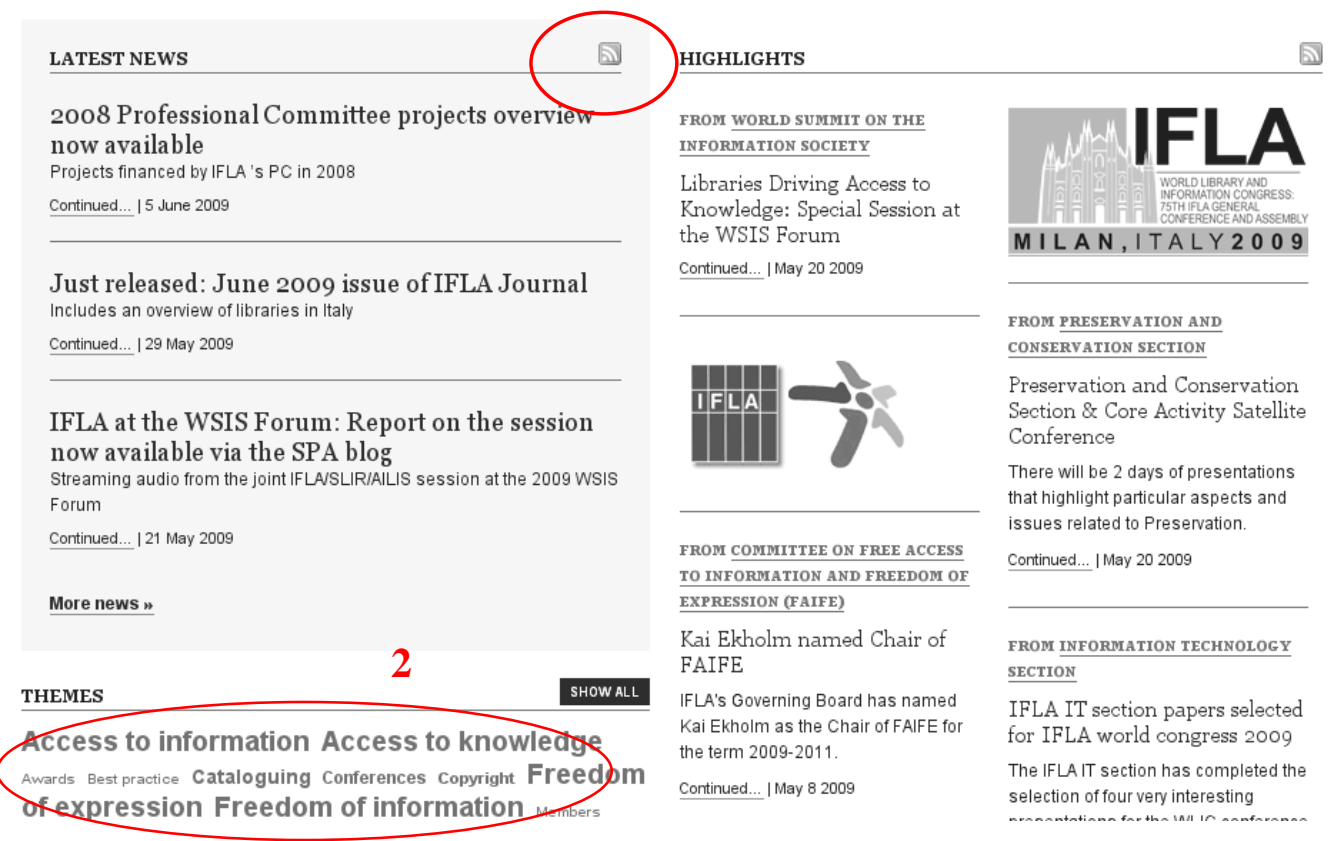

Fig.4. Screen shot displaying Web 2.0 features of the new IFLA site (1.RSS, 2. Topic clouds).

\subsection{Special Libraries Association (SLA) ${ }^{1}$}

SLA launched the first version of its Web site in 1996. The home page was redesigned in early 1997, which lasted until October 2000. Keeping the old Web site up-to-date and fresh required many hours of work for the few staff members who knew how to create HTML pages. It became clear that each program area of the association needed the ability to get data to the Web site quickly, efficiently and consistently. The 2000 version is a database-driven, customdeveloped content management system running on the latest software and hardware. The new system spread the responsibility of posting and maintaining the Web site from a few technical resources to every program area. This enabled the association to be more responsive to the membership. Weaknesses in the design of the software have caused the site to become bulky, difficult to navigate and inaccurate to key-word search (Latham, 2004).

\footnotetext{
${ }^{1}$ http://www.sla.org
} 
Although minor amendments were made to improve accessibility to the SLA Web site's resources, it became clear from user surveys, discussion list feedback and general comments from the members that it was time for a general overhaul. SLA decided that a $62 \%$ satisfaction rate in the 2002 Needs Assessment Survey was unacceptable.

Therefore to better accommodate the needs of SLA members, and promote the association worldwide, SLA started a Web site redesigning drive in 2004 (Ibid.).

Not only did SLA considered accessibility to the whole Web site, but also the design of the home page as a promotional tool of the association as a whole. SLA's marketing team took on the task of redesigning the home page and changing the structure of the site.

The Web team solicited the help of SLA members to participate in Web focus groups. Questionnaires were also distriuted to far away members. Finally an appropriate design was agreed upon.

Here are some of the remarkable features of the new site SLA highlights.

1. Accessing the Member's Only Section

Members will no longer have to remember PIN as the new website allows to set their own passwords for the member only resources. In addition they will now be able to save a cookie to their own computers to have instant access to members only resources.

2. Knowing Where You Are

A 'crumb-trail' has been added to the Web site to clearly show current location within the site, and simplify navigation. 


\subsection{SLA Biomedical \& Life Sciences Division (SLA DBIO) ${ }^{1}$}

DBIO launched its site in August 2007, after a period of a complete year's hard work (DBIO, 2007).

"Our goals for the new web site redesign are to promote the Division's image and services; increase membership; facilitate twoway communication; encourage initial and return visits through improved usability and appeal; and capture the interest of our members and potential members by its format, ease of use, attractiveness, color, and identifiable logos. It is expected that the redesign will create an infrastructure that makes the site easier to maintain, to add new content and to make future improvements. The DBIO web site is hosted by SLA, our parent organization".

Site updating and editing was done offline using Adobe Contribute $\mathrm{CS}^{2}$. With Contribute, the webmaster can publish content directly from within Microsoft Office applications with the click of a button (Ibid.). This shows how much concerned associations are, on easy publishing standards. Unlike software companies, professional associations have other priorities, while, at the same time try to support their users utilizing the latest developments in ICT.

\subsection{Sri Lanka Library Association (SLLA) ${ }^{3}$}

Previously, SLLA Web site was only an extention of the National Science Foundation Web site. In 2001-2002, SLLA purchased its own domain name, incorporating both organisational (org) and the country specific (lk) domains. It is not uncommon for any given domain to undergo this type of wholesale restructuring (Koehler, 2004).

\footnotetext{
${ }^{1}$ http://units.sla.org/division/dbio/

${ }^{2}$ Adobe Contribute software enables users to collaboratively author, review, and publish web content while maintaining site integrity — without learning HTML.

${ }^{3}$ http://www.slla.org.lk
} 
“...for example, the American Library Association, owner and manager of www.ala.org completely changed the file tree with "catastrophic consequences" for many of us maintaining links to ala.org. Similarly, when management of the International Federation of Library Associations and Institutions (IFLA) Web site migrated from Canada to France, the IFLA Committee on Free Access to Information and Freedom of Expression (FAIFE) Web site was subsumed under the IFLA umbrella and converted from faife.dk to ifla.org/faife/".

(Koehler, 2004).

This action is commendable as The Scholarly Societies Project at the University of Waterloo has observed that canonical URLs - those that took the form www.orgname.org and www.orgname.org.cc are more likely to persist than other non-canonical forms. Thus, as a strategic collection decision, one might preclude Web documents that do not meet some 'persistence test' such as the canonical URL in an effort to build more stable collections (Ibid.).

SLLA had Web site redesigning projects in 2006 and 2008. The main changes were bringing more information to the home page, improving look \& feel, and allowing easy updation. It includes a section for news and events, which is very much useful for the membership to get updated themselves about SLLA events. 


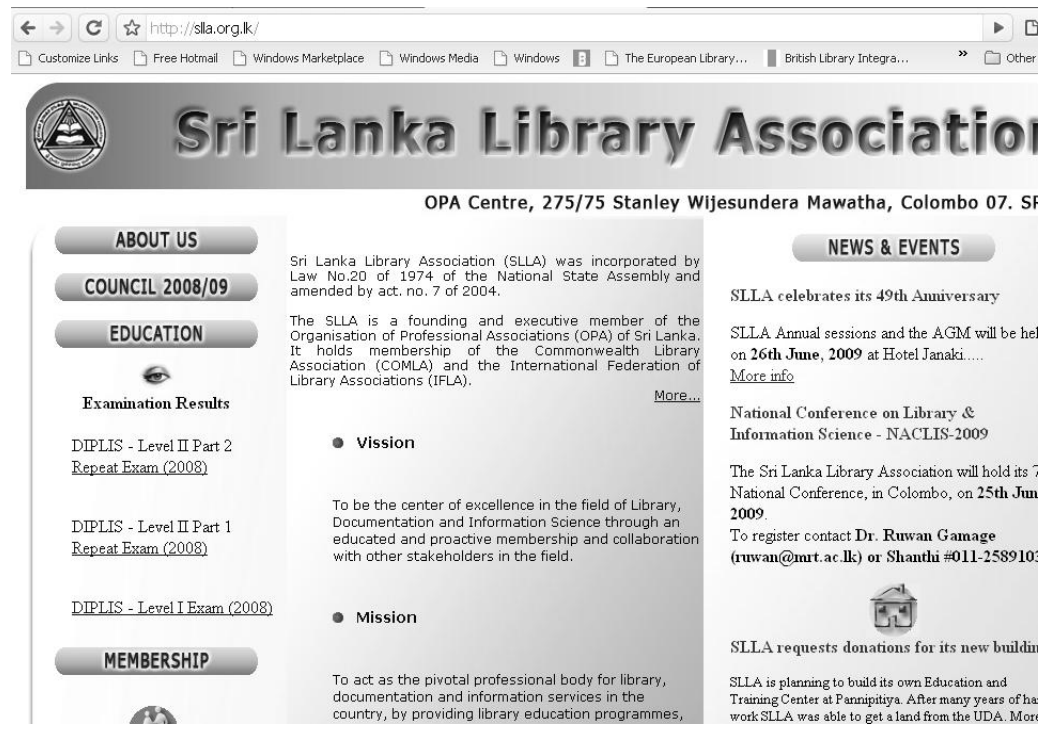

Fig. 5. SLLA Web site

\section{Conclusion}

Continuous updation and frequent renovation is necessary for any web site. Library associations increasingly seem to incorporate this fact into their agendas. However, these renovations will be more useful if based on proper user studies. Focus groups and user surveys will be appropriate tools for this. It would be more beneficial to have a web team including professionals and ICT specialists, rather than depending on activities of a single person. Such action would lead to a more standard and persistant web site.

Two way communication is the main identifiable feature of most of the renovated library association web sites concerned. This helps maintain dialog, rather than monologue between the organisation and its users. In addition, features like blogs, and feedback facilities enable dialogue among users, which is a new benefit which was previously unpredicted.

Along with Web site designing becoming an act of the non-IT professional too, roles of library association leaders also become extended. They are no longer at the receiving end with regard to IT and web designing. They also become 
contributors, because everyone is empowered with the availability of tools for easy handling of Web sites. Social networking and collaboration become the norms of the Web 2.0 world.

Through content creation, hosting, and becoming the common stage, library association web sites become messengers, promotors, ambassadors, think tanks, and visionaries. It can also become the 7/24 low-cost (or even no-cost) customer care service point.

Yet, the developers should maintain a policy on which information to post, and which technologies/facilities to be enabled. Otherwise Web 2.0 technologies will take us nowhere. At this point, it is appropriate to quote the Nobel price winner economst Herbert Simon's viewpoint...

"What information consumes is rather obvious: it consumes the attention of its recipients. Hence a wealth of information creates a poverty of attention, and a need to allocate that attention efficiently among the overabundance of information sources that might consume it."

- Herbert Simon, 1971.

\section{References}

Craven, Jenny. (2008). Web accessibility: what we have achieved and challenges ahead. World Library and information Congress: $74^{\text {th }}$ IFLA General Conference and Council. 10-14 August 2008, Québec, Canada.

Koehler, Wallace. (2004). A longitudinal study of Web pages continued: a consideration of document persistence. IR Information Research. 9 (2). Available in http://informationr.net/ir/9-2/paper174.html. Accessed 20.06.2009.

Latham, J. Redesigning the special libraries association web site. Information Outlook. 8(1), pp. 10-11. Jan. 2004 
Journal of the University Librarians Association of Sri Lanka. Vol.13 (Issue 1). 2009

New IFLA Web site. www.ifla.org.sg/l/whatsnew/new-website-overview.pdf. Accessed 20.06.2009.

SLA Web site redesign Project. http://units.sla.org/division/dbio/inside/redesignold.html. Accessed on 20.06.2009.

Simon, H. A. (1971), "Designing Organizations for an Information-Rich World", in Martin Greenberger, Computers, Communication, and the Public Interest, Baltimore, MD: The Johns Hopkins Press. 